\title{
The Effects of MDMA and Methamphetamine on Car Driving Simulator Performance, Cognitive Skills, and Mood States
}

\author{
C. Stough", E. Ogden, K. Owens, P. Swann, A. Gibbs, A.C. Parrott, K. Wesnes and R. King \\ Drugs and Driving Research Unit (DDRU), Brain Sciences Institute, Swinburne University, Melbourne, Australia
}

Keywords: MDMA, Ecstasy, driving, cognition, mood.

\section{INTRODUCTION}

The aim of this study was to investigate car driving skills and cognitive abilities after the consumption of methamphetamine and MDMA. In previous studies we have demonstrated significant decrements following sedative drugs such as cannabis, and stimulants such as dexamphetamine [1]. We have also documented the presence of stimulant drugs in many fatal traffic accidents, especially those involving road-train truck drivers in Australia [2]. There is however disagreement over whether acute doses of MDMA will impair or improve cognitive function and driving behaviours in humans. Ramaekers $e t$ al. [3] reported that an acute dose of 75mg MDMA improved tracking accuracy, but impaired speed adaptation during carfollowing. Dastrup et al. [4] noted that abstinent Ecstasy users were not impaired on car driving skills, but did assume extra risk. In an analysis of traffic accidents involving stimulant drugs, Verschraagen et al. [4] reported more fatalities involving MDMA than amphetamine. The present study was funded by an Australian Research Council Discovery Grant (DP0772762) to Professor Stough, Dr. Owens, and Dr. Ogden.

\section{METHOD}

We tested 61 participants (29 female and 31 male) aged between 21 and 35 years $(\mathrm{M}=25.34 \mathrm{SD}=3.26)$. All participants were in good health, had a valid full drivers license (no probationary or learner drivers), and were recreational stimulant drug users. The project consisted of three experimental sessions that involved the consumption of $100 \mathrm{mg}$ of MDMA, $42 \mathrm{mg} / \mathrm{kg}$ Methamphetamine, and placebo. Each experimental session incorporated an acute testing phase at 3hours post-drug administration as well as a follow up at 24 hours post-drug to assess any residual affects the drugs may have on performance. The 3 sessions were double blind, counter-balanced and placebo controlled. Driving skills, cognitive ability, mood state, and blood samples, were assessed at each testing point.

\section{RESULTS}

Performance on the following car driving measures were significantly worse when under the influence of MDMA three hours post drug (compared to placebo): signal changes, dangerous action skidding, inappropriate braking, safe following distance, speed in the city, and overall driving score. Performance on the stopping brake measure was significantly worse when under the influence of methamphetamine three hours post drug (when compared to placebo). Driving performance improved at 24 hours post-drug administration compared to 3 hours in the MDMA and methamphetamine conditions. Impairment due to MDMA relative to placebo was also observed in the quality of episodic memory from the Cognitive Drug Research test battery; the latter effect was highly significant. Positive mood state changes were not observed following MDMA, whereas they did occur following acute methamphetamine. Against expectations, negative moods were significantly higher 3 hours after acute MDMA than placebo.

\section{CONCLUSIONS}

Car driving performance was significantly impaired on a number of performance variables during intoxication by MDMA. This adds to the limited empirical information on car driving skills related to Ecstasy/MDMA [3-5]. Less driving impairment was observed in the methamphetamine condition, this may be attributed to the stimulant effects of small doses of methamphetamine administered.

\section{REFERENCES}

[1] Silber BY, Papafotiou K, Croft RJ, Ogden E, Swann P, Stough C. The effects of dexamphetamine on simulated driving performance. Psychopharmacology 2005; 179: 536-43.

[2] Drummer OH, Gerostamoulos J, Batziris H, et al. The involvement of drugs in drivers of motor vehicles killed in Australian road traffic crashes. Accid Anal Prev 2004; 36: 239-48.

[3] Ramaekers JG, Kuypers KP, Samyn N. Stimulant effects of 3,4methylenedioxymethamphetamine (MDMA) $75 \quad \mathrm{mg}$ and methylphenidate $20 \mathrm{mg}$ on actual driving during intoxication and withdrawal. Addiction 2006; 101: 1614-21.

[4] Dastrup E, Lees MN, Bechara A, Dawson JD, Rizzo M. Risky car following in abstinent users of MDMA. Accid Anal Prev 2010; 42: 867-73.

[5] Verschraagen M, Maes A, Ruiter B, Bosman IJ, Smink BE, Lusthof KJ. Post-mortem cases involving amphetamine-based drugs in The Netherlands. Comparison with driving under the influence cases. Forensic Sci Int 2007; 170: 163-70.

*Address correspondence to this author at the Drugs and Driving Research Unit (DDRU), Brain Sciences Institute, Swinburne University, Melbourne, Australia; Tel: +61 39214 8167; E-mail: cstough@swin.edu.au 